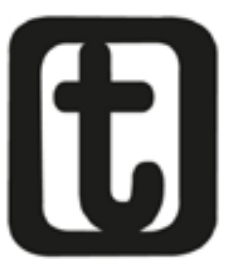

\title{
POPULAÇÕES EM SITUAÇÃO DE RUA: OS PROCESSOS DE EXCLUSÃO E INCLUSÃO PRECÁRIA VIVENCIADOS POR ESSE SEGMENTO
}

Homeless population: the precarious exclusion and inclusion processes experieced by this segment

\author{
Jane Cruz Prates ${ }^{1}$ \\ Flavio Cruz Prates ${ }^{2}$ \\ Simone Machado3
}

\section{RESUMO}

O presente artigo problematiza os processos de exclusão e inclusão precária vivenciados por sujeitos que habitam as ruas dos grandes centros urbanos, marcados por processos de discriminação e estigmas, não só de parte da sociedade em geral, mas também daqueles que, a partir da oferta de serviços públicos, deveriam buscar a garantia de seus direitos. Analisa a realidade dos sujeitos em situação de rua a partir de dados nacionais e internacionais que dão visibilidade a suas características e condições de vida, identificados através de diversos estudos, entre os quais alguns realizados em

\footnotetext{
1 Jane Cruz Prates é Assistente Social, mestre e doutora em Serviço Social, Professora da FSS (PUCRS) e do PPGSS (PUCRS), Coordenadora do Programa de Pós-Graduação em Serviço Social da PUCRS, Coordenadora do Grupo de Estudos sobre Teoria Marxiana, Ensino e Políticas Públicas (GTEMPP) da PUCRS, pesquisadora produtividade do CNPq. E-mail: <jprates@pucrs.br>.

${ }^{2}$ Flavio Cruz Prates é Advogado, mestre em Ciências Criminais e doutor em Serviço Social pela PUCRS, professor da Faculdade de Direito da PUCRS. E-mail: <fprates@pucrs.br>.

${ }^{3}$ Simone Machado é Assistente Social da Fundação de Assistência Social e Cidadania (Fasc da PMPA), mestranda em Serviço Social pelo PPGSS (PUCRS), pesquisadora do GTEMPP. E-mail: <smachado@fasc.prefpoa.com.br>.
} 
Porto Alegre, dos quais os autores foram pesquisadores. Aborda, de modo sucinto, os eixos, diretrizes e estratégias previstas pela recente política de inclusão social para populações em situação de rua que vem sendo implantada no Brasil e aponta algumas sugestões para a intervenção social nessa área.

\section{PALAVRAS-CHAVE}

Populações em situação de rua. Políticas públicas. Exclusão e inclusão precária. Processo de rualização.

\section{ABSTRACT}

The present article discusses the precarious exclusion and inclusion processes experienced by individuals living on the streets of large cities. This population is marked by processes of discrimination and stigmatization not only by society in general, but also by those who should use the offer of public services to grant these people their rights. The study analyzes the reality of homeless individuals based on Brazilian and international data on their characteristics and life conditions, which are identified through several studies such as those in Porto Alegre, having their authors as researchers. The present study briefly approaches the axes, guidelines, and strategies planned by the recent social inclusion policy for the homeless that has been implemented in Brazil, and offers a few suggestions for social intervention in this field.

\section{KEYWORDS}

Homeless Population. Public Policies. Precarious exclusion and inclusion. Process of homelessness. 


\section{INTRODUÇÃO}

A primeira questão que se pretende problematizar em relação ao debate sobre sujeitos em situação de rua são as expressões utilizadas para caracterizar esse segmento populacional e os conceitos a elas associados, nem sempre muito precisos. Não há dúvidas de que, para além de expressões e conceitos que podem reiterar processos excludentes, a desigualdade concreta vivenciada por eles é a questão central, e não será a precisão do modo como os caracterizaremos que irá reduzir essa desigualdade. Por outro lado, a melhor precisão de conceitos pode auxiliar estudos e pesquisas que, ao darem visibilidade a essa realidade, ao levarem para o debate público esses questionamentos, ao subsidiarem propostas e políticas contribuam com estratégias para a redução dessas desigualdades e o fortalecimento das resistências empreendidas por esses sujeitos.

Severino (2002, p. 187), “[...] o raciocínio é o momento amadurecido do pensamento; raciocinar é encadear juízos e formular juízos é encadear conceitos". Logo, diz o autor, o conhecimento humano inicia-se com a formação de conceitos.

Ao analisarem-se, por exemplo, expressões como deambulantes ou andarilhos associadas à situação de rua, tem-se a caracterização de um sujeito que vive deslocando-se, o que não é um traço comum a esse segmento populacional. O nomadismo dos andarilhos que caracteriza alguns destes sujeitos é, em outros, resultado de sua expulsão de locais onde, por um período, foram aceitos e, em outro momento, são rejeitados, seja porque acumulam objetos no espaço da rua, fazem uso de drogas, têm delírios ou simplesmente porque sua presença incomoda os moradores do bairro, que por determinado período aceitaram sua permanência, ocupando de modo privado o espaço público. Considerando suas características diversas que variam entre o andarilho solitário, famílias que habitam pontes, viadutos, parques ou terrenos baldios, loucos de rua que vivem sozinhos e pequenos grupos que permanecem em locais mais ou menos fixos, deslocando-se para abrigar-se das intempéries, mas no âmbito de um mesmo bairro, e aqueles que cir- 
culam entre abrigos e albergues públicos, os mais diversos estudos reconhecem que se constituem como um segmento heterogêneo.

Considerar que um sujeito é de rua seria o mesmo que considerar que alguém é de casa ou de apartamento. Vive-se em casas, apartamentos ou, no caso do segmento analisado, no espaço da rua, e esta pode ser uma situação contingente. Ver essa situação como estado e não como processo é um modo de reiterá-la, sem reconhecer a perspectiva do movimento de superação - e essa parece ser uma questão central. Estar em situação de rua ou habitar a rua é diferente de ser de rua. Vista como determinação, uma situação social pouco apresenta em termos de perspectivas de superação. O termo processo de rualização parte de uma concepção oposta, na medida em que o reconhece como processo social, condição que vai se conformando a partir de múltiplos condicionantes, num continuum, razão pela qual processos preventivos e a intervenção junto àqueles que estão ainda há pouco tempo em situação de rua parecem ser fundamentais para que se logre maior efetividade em termos de políticas públicas.

Outra confusão frequente que se verifica na caracterização desse segmento populacional é referenciá-los como mendigos. Mendigos são aqueles que praticam a mendicância, que esmolam em sinaleiras, nas ruas, na porta de prédios públicos. Muitos dos sujeitos que habitam as ruas não praticam a mendicância, o que foi explicitado em estudo do tipo censo realizado em Porto Alegre com sujeitos adultos em situação de rua (REIS; PRATES; MENDES, 1995). Mostra o estudo que, de um total de 222 moradores de rua que, na ocasião, viviam na cidade, $47,5 \%$ costumavam esmolar, 50,2\% recebiam alimentos da comunidade e $47 \%$, outros auxílios como roupa, cobertores, dinheiro - o que foi reiterado por estudo, de mesmo tipo, realizado 5 anos depois no mesmo município (ABREU et al., 1999).

Uma pesquisa nacional sobre população em situação de rua, realizada em cidades brasileiras com mais de 300 mil habitantes, pelo Ministério de Desenvolvimento Social (MDS) em 2008, mostra que apenas $16 \%$ desses sujeitos pedem dinheiro para sobreviver ou praticam a mendicância, logo, é um equívoco atribuir essa prática ao 
conjunto da população que habita as ruas dos grandes centros urbanos. O referido estudo mostra também que $59 \%$ dos pesquisados afirmaram ter profissão, principalmente relacionada à construção civil, ao comércio, ao trabalhado doméstico e ao serviço de mecânica, embora $48 \%$ tenham afirmado que nunca tiveram a carteira de trabalho assinada (BRASIL, 2008a).

Alguns sujeitos que utilizam o espaço da rua como sobrevivência, seja para a prática de mendicância, seja para a realização de trabaIhos geralmente precários, como cuidar de carros ou fazer outros biscates, retornam para suas casas no final do dia e, portanto, não se caracterizam como alguém que habita as ruas.

Conceitos como os utilizados pela Organização das Nações Unidas (ONU), que ampliam a concepção de sujeitos em situação de rua para os que vivem em habitações precárias, malocas e favelas ou incluem todos aqueles que vivem em lugares cuja habitação não atende aos padrões mínimos de habitabilidade, não podem, por exemplo, ser utilizados em estudos realizados por países que têm níveis de desigualdade como os latino-americanos, porque o continente tem um enorme contingente de pessoas que vivem em sub-habitações e esse alargamento conceitual acabaria por dificultar a caracterização destes que vivem no espaço da rua. Contudo, essa referência parece importante para que se possa refletir sobre o significado do habitar em condições dignas como uma necessidade humana fundamental e privilegiar iniciativas que incidam sobre esse tema, de igual relevância, para o enfrentamento da desigualdade social, especialmente em países como o Brasil, que tem um déficit histórico tão significativo nessa área. Questões como a reforma agrária e a regulamentação fundiária são temas centrais e condição necessária ao enfrentamento efetivo da desigualdade social e da pobreza. A concentração da renda e da terra está na raiz da histórica desigualdade que caracteriza os países latino-americanos.

Mas a conceituação mais precisa e a visibilidade às características dos sujeitos podem contribuir para o alongamento do olhar, pois, como bem dizia Marx (1993), o olho que não aprende a ver não en- 
xerga, é preciso educar os sentidos, assim como se educa a razão, porque é através deles que se captura o mundo sensível.

No Brasil, a política nacional para inclusão social das populações em situação de rua é bastante recente, teve sua aprovação em maio de 2008, embora o Sistema Único de Assistência Social (Suas) (2006) já contemplasse esse segmento nos programas e serviços contidos na Proteção Especial de média e alta complexidade.

Conforme a Política, essa população é definida como aquela que "[...] faz das ruas seu espaço principal de sobrevivência e de ordenação de suas identidades" (BRASIL, 2008), ou seja, além daqueles que habitam as ruas, o conceito abarca aqueles que têm a rua como referência, a partir da qual constituem sua identidade, reconhecendo que o processo de rualização impacta na constituição de sua subjetividade.

Em consultoria realizada para subsidiar a elaboração da política, foi realizado estudo qualitativo pelo MDS com sujeitos em situação de rua em diferentes estados do Brasil (BRASIL, 2008). Os pesquisados destacaram a importância do trabalho realizado para superação do processo de rualização, embora reconheçam a complexidade e dificuldade para efetivação desse movimento, o que será explicitado ao longo do presente artigo, a partir do aporte de suas próprias expressões.

Ainda que uma diversidade de estudos realizados no Brasil e no mundo 4 sobre sujeitos em situação de rua mostre que não só o desemprego tem sido fator determinante para condicionar processos de rualização, a centralidade do trabalho aparece na expressão dos sujeitos de modo significativo.

O trabalho, na expressão de um dos entrevistados, é visto como "[...] a primeira porta que se abre" (BRASIL, 2008) e que oferece oportunidades para suprir necessidades como alimentos, banho, pousada. Destacam, contudo, que as atividades dirigidas para a

${ }^{4}$ Reis; Prates; Mendes (1994); Slagg, Lyons e Cook (1994); Rosa (1995); Yazbek (1992); Dixon (1995); Zlotnick e Robetson (1996); Snow e Anderson (1998); Prates, Reis e Abreu (2000); Abreu et al. (1999); Bulla; Mendes; Prates (2004). 
capacitação dos sujeitos que antecedem esses processos são de fundamental importância, pois incidem sobre sua autoestima recuperando sua dignidade perdida. Acreditar em si próprios e que é possível ressignificar trajetórias é o primeiro passo para que possam progressivamente superar o processo de rualização, afirmam os sujeitos (BRASIL, 2008).

Ao expressarem a representação que fazem do lugar que os referencia, trazem suas histórias de vida marcadas por perdas diversas, da casa, do emprego, da família, da autoestima, por culpas e uso abusivo de álcool, aspectos comuns amplamente confirmados por estudos realizados com moradores de rua, em âmbito mundial e em grandes metrópoles brasileiras (VIEIRA, 1992; REIS; PRATES; MENDES, 1994; SLAGG; LYONS; COOK, 1994; ROSA, 1995; YAZBEK, 1992; DIXON et al., 1995; ZLOTNICK; ROBETSON, 1996; SNOW; ANDERSON, 1998; PRATES; REIS; ABREU, 2000; ABREU et al., 1999; BULLA, MENDES, PRATES, 2004; SCHUCH et al., 2008).

Por outro lado, é sempre importante reiterar que nenhum fenômeno social se origina de uma única causa, mas de múltiplas determinações, logo, seu enfrentamento requer a articulação de iniciativas diversas, o que tem sido um problema histórico no Brasil: superar a fragmentação e garantir intervenções pautadas na integralidade.

\section{A DESIGUALDADE EXPRESSA NAS CONDIÇÕES DE VIDA, REITE- RADA PELO IMAGINÁRIO SOCIAL E PELA INTERDIÇÃO DO ACESSO}

Estudos que fazem a escuta dos sujeitos que habitam as ruas das grandes cidades e que avaliam essas experiências a partir do olhar dos próprios sujeitos constatam histórias e cotidianos marcados por perdas, exclusão, subalternização e desqualificação, confirmando pesquisas efetivadas com técnicos e grupos específicos que também aportam relatos similares (ABREU et al., 1999; BULLA; MENDES; PRATES, 2004; REIS; PRATES; MENDES, 1994; SNOW; ANDERSON, 1998; YAZBEK, 1992; SCHUCH et al., 2008).

Verifica-se, em suas expressões, o que se pode chamar de autoexclusão, ou seja, o não reconhecimento de si próprios 
como sujeitos de direitos, como parte integrante da sociedade inferência realizada a partir da expressão de um dos entrevistados: "[...] eu era, antigamente, como bem dizer, da sociedade [...]" (FARIAS, 2007). Essas palavras refletem a internalização, por parte dos sujeitos moradores de rua, de uma imagem desqualificada, reiterada pelo estigma com que são tratados pela sociedade, 0 que os leva, em algumas situações, a isolamentos quase absolutos, conforme destaca Paugam (1999).

Ainda segundo Paugam (1999), a desqualificação social, uma das faces do processo de exclusão, é humilhante e interfere na qualidade de relações, incitando o fechamento do sujeito sobre si mesmo e a perda de referências. A culpa resultante de uma visão reduzida da realidade amplia o processo. O não reconhecimento de situações, por exemplo, de desemprego, como uma expressão da questão social, condicionada, portanto, por fatores conjunturais e estruturais e não por "[...] incompetências individuais [...]"; ou por não reconhecer o alcoolismo como doença, que necessita de tratamento, faz com que a autoculpabilização, expressa na fala de muitos entrevistados, acentue o sentimento de fracasso e a baixa autoestima, o que, numa condição adversa, de falta de oportunidades, pode significar a desistência e a acomodação nessa condição de sobrante - para usar uma expressão de Castel (2000).

A dependência química, em especial a do álcool, mencionada reiteradamente nas falas dos diversos entrevistados pelo estudo realizado em nível nacional (BRASIL, 2008), desde muito é tematizada nos estudos sobre populações em situação de rua, em nível internacional e nacional (VIEIRA et al., 1992; REIS; PRATES; MENDES., 1994; SLAGG; LYONS; COOK, 1994; ROSA, 1995; YAZBEK, 1992; DIXON et al., 1995; ZLOTNICK; ROBETSON, 1996; SNOW; ANDERSON, 1998; PRATES; REIS; ABREU, 2000; ABREU et al., 1999; BULLA, MENDES, PRATES, 2004). Além disso, os autores desses trabalhos são enfáticos ao apontar a necessidade de integração entre as políticas sociais para enfrentamento às situações de rualização, destacando a importância de que seja garantido a esse segmento o acesso ao tratamento na área da saúde mental de modo articulado a outras políticas. 
A expressão dos entrevistados reafirma que os processos de drogadição condicionam perdas diversas, do emprego, da família, da autoestima, reiterando que o fenômeno da rualização não pode ser atribuído a uma única causa.

Morava com meus pais, mas tinha o problema do alcoolismo, não dava pra conviver bem com meus pais, sempre brigando, meu pai recriminando [...]

[...] a maioria das pessoas que está na rua é pai de família, a maioria tem tudo quebrado por causa do álcool, das drogas e até por causa do próprio desemprego, porque às vezes a pessoa perde o emprego, começa a passar dificuldades em casa e aí já cria aquele tumulto com a esposa e os filhos, acaba separando e aí a pessoa entra na depressão, e acaba parando na rua (BRASIL, 2008).

Slagg; Lyons e Cook (1994), em estudo realizado sobre desabrigados de Chicago cobertos por programa de reabilitação, observou que mais de $70 \%$ desses sujeitos apresentavam algum transtorno mental identificado, sendo que $16 \%$ apresentavam problemas com álcool e $12 \%$ com outras drogas. O mesmo autor referencia situações de problemas familiares, chegando à ruptura de vínculos, em alguns casos. As expressões dos sujeitos entrevistados, anteriormente mencionadas, associam o problema do alcoolismo a problemas com familiares e à fragilização ou perda de vínculos diversos.

Teeson (1993) e Zlotnick; Robetson (1996) observaram que desabrigados com transtorno mental por uso de substâncias químicas tinham menos habilidade para procurar trabalho, ficando mais isolados socialmente. Caton (1993) também observou o efeito desfavorável do abuso de substâncias psicoativas que, segundo o autor, ocasionavam a redução de capacidades. Em acompanhamento realizado por 18 meses a moradores de rua com problemas mentais, o autor observou que grande parcela dos resultados negativos do programa de reabilitação devia-se à presença do diagnóstico de abuso ou dependência de substâncias químicas (CATON, 1993).

Em um primeiro censo realizado em Porto Alegre sobre sujeitos em situação de rua (REIS; PRATES; MENDES, 1994), foi constatada a existência de um número de 222 moradores de rua, maiores de 14 
anos, na cidade. Nesse estudo, os principais motivos citados pelos entrevistados como justificativa da busca da rua como espaço de moradia foram problemas de relacionamento familiar $(28,8 \%)$ e a dependência de álcool/drogas (22,5\%). O mesmo estudo mostra que, como características comuns, esses sujeitos apresentavam histórias de sucessivas perdas, o que confirma as observações expressas pelos entrevistados nos estudos subsequentes.

Em estudo realizado por Abreu et al. (1999) sobre condições sociais e de saúde mental de moradores de rua no mesmo município, a dependência química, em especial a de álcool, apresentou uma incidência da ordem de $69,1 \%$, o que pode ser melhor visualizado no quadro seguinte, que demonstra a gravidade da problemática e a necessidade urgente de priorização do tratamento em saúde mental para dar conta do seu enfrentamento.

\section{Quadro}

Moradores de rua segundo o uso de álcool e outras drogas

\begin{tabular}{|l|c|c|c|}
\hline & Homem & Mulher & Total \\
\hline Faz uso de álcool * & $95(74,2 \%)$ & $16(43,2 \%)$ & $111(67,3 \%)$ \\
\hline Uso diário de álcool * & $71(75,5 \%)$ & $05(31,3 \%)$ & $76(69,1 \%)$ \\
\hline Média de consumo diário de álcool & $\begin{array}{c}385,3 \mathrm{~g} / \mathrm{d} \\
\mathrm{dp}=311,8 \mathrm{~g} / \mathrm{d}\end{array}$ & $\begin{array}{c}421,2 \mathrm{~g} / \mathrm{d} \\
\mathrm{dp}=432,3 \mathrm{~g} / \mathrm{d}\end{array}$ & \\
\hline Outras drogas (inclui tabaco) ** & $100(79,4 \%)$ & $22(59,5 \%)$ & $122(74,8 \%)$ \\
\hline
\end{tabular}

*p $<0,001, * * \mathrm{p}<0,01$. Fonte: Abreu et al. (1999).

Todos os estudos realizados em âmbito nacional, local ou mesmo os estudos internacionais consultados mostram a predominância masculina nos processos de rualização. $O$ estudo realizado pelo MDS mostra que $82 \%$ dos pesquisados são homens (BRASIL, 2008), e o estudo realizado por Abreu et al. (1999) em Porto Alegre aponta um percentual de $76,8 \%$ de população masculina. Contudo, o estudo realizado no Brasil refere que o número de mulheres vem crescendo e, quando se encontram em situação de rualização, a vulnerabilidade a que estão sujeitas é ainda maior por sua condição de gênero. A expressão de uma das pesquisadas no estudo realizado pelo MDS (BRASIL, 2008a) explicita parte desse processo: 
O número feminino, ele é menor, mas ele está crescendo. E as mulheres, elas são mais [...]. Mais, ainda, vulneráveis. É muito mais difícil a mulher na rua do que o homem. Eu considero, não tem nenhuma pesquisa que diga isso. Mas ela 'enlouquece' muito mais rápido, têm [sic] problemas de saúde mental muito mais presentes nas mulheres. Não que não tenha nos homens, porque também usam bebida e etc... Mas a mulher, quando ela vai para a rua, ela já está mentalmente bem comprometida.

Diversos estudos, embora não versem especificamente sobre a questão da mulher moradora de rua, confirmam o exposto pela entrevistada. O número de mulheres é significativamente menor do que o de homens, elas correspondem a aproximadamente 30\% desse universo, segundo dados dos vários estudos realizados sobre populações em situação de rua no Brasil nas últimas duas décadas (VIEIRA et al., 1992; REIS; PRATES; MENDES, 1994; ABREU et al., 1999; BULLA, MENDES, PRATES, 2004). A violência sofrida por mulheres como condicionante dos processos de rualização é destacada por Cezimbra (2001) e por Browne (1993).

Conforme Prates, Abreu e Cezimbra (2004), a partir de estudo realizado em Porto Alegre com mulheres em situação de rua, confirma-se não só a fragilidade desse segmento em termos de saúde mental, mas uma desvalorização de si associada à perspectiva de gênero que se expressa numa postura de subalternidade verificada na busca pelo trabalho, no modo como se relacionam com seus parceiros ou mesmo na banalização da violência que sofrem no espaço da rua.

Para a moradora de rua, o trabalho profissional feminino, por exemplo, é visto como tarefa e não como trabalho, portanto, desvalorizado; ou ainda como algo determinado ou limitado pela condição feminina, reiterando a lógica excludente de que para a mulher devem destinar-se apenas as tarefas domésticas - é o que pode ser observado nas expressões de algumas das moradoras de rua entrevistadas em Porto Alegre por Abreu et al. (1999):

Só o homem trabalha, mulher faz serviço de mulher. Gostaria de um emprego numa casa de família, que eu tivesse um quartinho. 
Quero trabalhar numa casa de família.

Gosto de trabalhar de doméstica [...]

Trabalho é varrer casa, lavar louça, encerar [...]

A contradição entre a importância do trabalho e a dificuldade desse segmento em acessá-lo são expressas com clareza por um dos entrevistados no estudo realizado pelo MDS, que ressalta o preconceito em relação àqueles que habitam as ruas:

A gente procura emprego, aí você tem que ter um local de referência onde você mora, tem que ter um telefone para contato, você tem que ter uma referência. E aí você vai dizer - moro na marquise? Aí você já é excluído, porque tem uma discriminação, ninguém vai dar emprego para morador de rua! Este cara deve ser um drogado, um ladrão, sei lá [...]. (BRASIL, 2008a).

Uma avaliação dos estudos existentes sobre moradores de rua em âmbito internacional e nacional reitera o expresso pelo entrevistado, tanto no que concerne à importância do trabalho para a reinserção desses sujeitos quanto à identificação de sua perda ou falta de acesso como um dos elementos centrais que determinam o processo de rualização e a manutenção dos sujeitos nessa condição (SNOW; ANDERSON, 1998; REIS; PRATES; MENDES, 1996; ABREU et al., 1999; BULLA, MENDES, PRATES, 2004; SCHUCH et al., 2008) entre outros.

A fala de uma das entrevistadas no estudo nacional (BRASIL, 2008a) mostra a importância de viabilizar a capacitação profissional ao morador de rua numa perspectiva mais ampla, que inclua o seu fortalecimento enquanto cidadão de modo que isso repercuta numa mudança no imaginário social.

[...] o trabalho de venda da revista não é fácil. Capacitar as pessoas para a atividade de venda, não é capacitar a pessoa para saber vender, na verdade o processo de capacitação das pessoas para fazer este trabalho é o fortalecimento da auto-estima dela. A pessoa deve se sentir capaz de se expressar, de se comunicar, de abordar um estranho para oferecer um produto, invertendo uma leitura que a sociedade tem de que aquele sujeito é o pedinte, ou é o vagabundo, quer dizer, então, é o resgate da identidade de trabalhador, enfim $[. .$. 
Capacitar para o trabalho, como bem destaca a entrevistada, requer mais do que a apreensão de habilidades e conhecimentos específicos; requer, antes, o fortalecimento da autoestima, a ressignificação de expectativas. O gráfico que segue mostra o significado atribuído ao trabalho por moradores de rua, explicitado no estudo realizado em Porto Alegre (ABREU et al., 1999).

\section{Gráfico}

\section{Morador de rua segundo significado atribuído ao Trabalho}

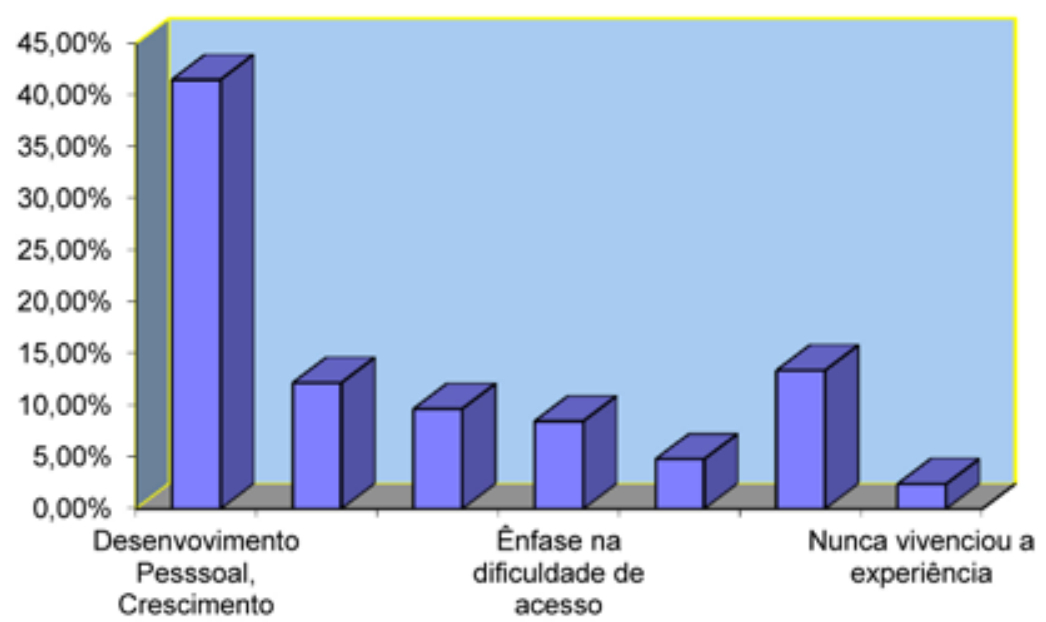

Fonte: Abreu et al. (1999).

O trabalho - mostram os diversos estudos sobre moradores de rua que avaliam a questão - é associado à ideia de saúde, de acesso ao lazer, de qualidade de vida, de segurança. A oportunidade de trabalhar é associada à possibilidade de novas perspectivas de vida, melhora da autoimagem, possibilidade de inserção e pertencimento. Trabalho, dizem os sujeitos,

\footnotetext{
É [...] possibilidade de 'estar bonito e ser admirado', 'trabalho é coisa linda, é tudo, é vida', 'trabalho é essencial ao homem, para sentir-se bem em qualquer lugar', 'trabalho é independência, é ter direitos é andar arrumado', 'trabalho é entrar na sociedade, é não ser marginal' (ABREU et al., 1999).
} 
Por outro lado, a ideia de perda do trabalho é relacionada à perda de identidade, perda de condições de vida e de autoestima: "[...] não ter trabalho é estar pesado, morto” (ABREU et al., 1999).

Segundo Paugam (1999): “Quando a pobreza é combatida e julgada intolerável pela coletividade [...] seu status social é desvalorizado e estigmatizante". Para o autor os processos de humilhação, desvalorização e discriminação vivenciados pelos segmentos mais excluídos conduzem a um estado de desqualificação social que impede os sujeitos de desenvolver um sentimento de pertencimento a uma classe social.

Bulla, Mendes e Prates (2004) ressaltam, utilizando a fala de um morador de rua entrevistado, a importância do emprego e sua vinculação com as demais expectativas desses sujeitos:

Eu quero ter uma oportunidade de ter um emprego, moradia e ter minha família em paz e se tiver ao meu alcance ajudar meus irmãozinhos que estão na rua [...] A única coisa, o meu sonho, é um trabalho e um teto para minha família, eu e minha mulher, quero ter a minha sobrevivência, eu prometo: se eu tiver um lar para ficar e um trabalho eu prometo, eu largo das drogas, eu largo da bebida (BULLA; MENDES; PRATES, 2004).

Contudo, as alternativas ofertadas de trabalho são pontuais e nem sempre efetivas, gerando expectativas que muitas vezes são posteriormente frustradas, como destaca uma das entrevistadas do estudo nacional:

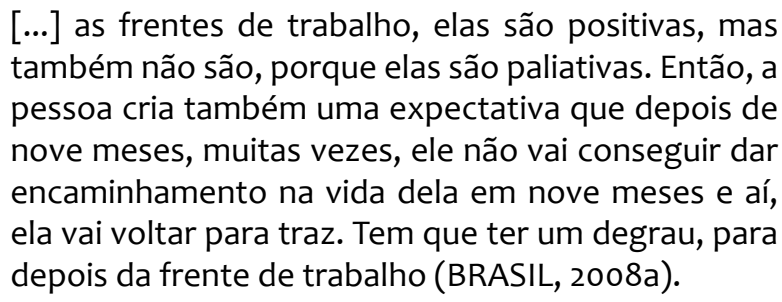

A questão do trabalho está vinculada ao imaginário social acerca do morador de rua, permeado por discriminação e estigmas.

Prates (2010), em estudo realizado sobre a população negra no 
Brasil, mostra as diferenças entre as concepções de discriminação e estigma, mas destaca que em sua efetivação estão muitas vezes relacionadas. Na discriminação de fato, diz o autor, existe uma invisibilidade de condutas pela ausência de um critério que justifique a exclusão de direitos, mas que acaba por fazê-lo por designar a restrição e o menosprezo aos direitos de um determinado grupo. Tal fator pode acontecer tanto consciente quanto inconscientemente.

Já na estigmatização, um grupo pode ser distinguido por características como laços de identificação, a história, a linguagem, a tradição e a experiência comum que os diferencia do grupo geral e pelas quais, muitas vezes, é discriminado.

No que concerne ao imaginário social sobre os sujeitos em situação de rua, a expressão de alguns entrevistados, durante o estudo realizado em nível nacional pelo MDS, mostra a invisibilidade e a estigmatização referidas por Prates (2010). Referem os pesquisados que a sociedade os vê como:

Vagabundos, drogados, bêbados e loucos, essa é a visão da sociedade e até de muitos técnicos em relação à população de rua...

$[\ldots]$

Lá, agora, o sub-prefeito quer terminar com os catadores, ele não quer mais catadores no centro de São Paulo, queria padronizar a carroça..., queria uma série de coisas. E quer mandar o pessoal, são 19 mil catadores no Centro, quer mandar lá para um bairro afastado.

$[\ldots]$

Só tenho uma resposta, eles não vêem o morado de rua... Eles não vêem, só vêem o lado deles. O negócio é o seguinte: eles têm medo de enxergar a realidade do morador de rua (BRASIL, 2008).

Destaca-se que não só a comunidade em geral, mas também lideranças públicas e técnicos, segundo a percepção desses sujeitos, os veem de modo estigmatizado, reiterando os processos de interdição de seus direitos, o que acaba por impactar na avaliação que fazem das políticas de atendimento: "Os moradores de rua são 
tratados ora com compaixão, ora com repressão, preconceito, indiferença e violência" (FRANCISCO, 2010).

Quanto às políticas, evidenciam-se a falta de integração e as ações restritas aatenções superficiais, quenão investem no fortalecimento e autonomização dos sujeitos, o que demanda o reconhecimento da complexidade da problemática, o planejamento integrado de ações e sua priorização enquanto intervenção realizada a partir de um conjunto articulado de políticas públicas de estado.

A expressão dos sujeitos usuários, pesquisados no estudo nacional, bem explicita esse processo a partir de suas vivências concretas na busca por serviços:

Estes dias fui levar um colega meu no médico. Chegando lá, o médico disse: 'Aqui não é lugar pra morador de rua, morador de rua tem que ir pra Pronto Socorro!' Só o fato de você ser morador de rua, o cara já te olha diferente, mas na área da saúde é que são mais discriminados. Inclusive até um amigo nosso faleceu e eu acho que foi por incompetência médica. Um morador de rua caiu e bateu a fronte, teve um traumatismo craniano, e aí foi para o hospital. Eu estava na praça quando aconteceu o acidente, quando ele caiu, e até fui eu que chamei o resgate... Porque a gente chama o SAMU e não vem, as ambulâncias do SAMU não vêm, sabendo que é morador de rua eles não vêm. Isto é descriminação! Aí veio o resgate, o bombeiro colocou até aquele colar cervical e levou ele para o Pronto Socorro. [...] Ele teve alta, mas a mãe dele nos falou que estava colocando sangue pelo nariz, pela boca. Quando o paciente tem alta do leito, ele para de receber a medicação, e aí ele faleceu [...] (BRASIL, 2008a).

Essas questões pertinentemente destacadas pelos entrevistados são reiteradas por pesquisas institucionais e estudos realizados em nível de Mestrado e Doutorado (OURIQUES, 2005; BORBA, 2005; FARIAS, 2007) que relatam a precariedade com que são atendidos esses sujeitos, por conta da falta de capacitação das equipes de trabalhadores públicos, em especial na área da saúde. Estudos que avaliam a relação da Política de Assistência Social com outras políticas, em especial as de inserção produtiva, saúde e habitação, rei- 
teram a dificuldade de efetivação desse atendimento de modo integrado, onerando serviços, retardando ou impedindo o progresso de processos de autonomização dos sujeitos e perdendo com isso alcance e efetividade (OURIQUES, 2005; BORBA, 2005; FARIAS, 2007).

Em pesquisa de mestrado realizado por Farias (2007), para avaliar as possibilidades de inserção produtiva de pessoas em situação de rua, a pesquisadora recebeu as seguintes respostas das agências de emprego em Porto Alegre:

[...] e eles trabalham?

Como posso referenciar uma pessoa sem domicílio?

Até poderia trabalhar como doméstica, mas sem endereço [...] e a aparência deles não é boa, melhor não perder o tempo deles nem o meu [...] (FARIAS, 2007).

Um estudo realizado por Bulla, Mendes e Prates (2004) em albergue municipal para atendimento a moradores de rua mostra que os albergados reivindicavam maior tempo de permanência tanto nos albergues quanto nos abrigos e a ampliação do número de vagas nos mesmos. Segundo as autoras, os usuários sugeriram uma maior articulação entre os albergues para que houvesse diferentes horários para a entrada nas instituições de albergagem, para que no caso de superlotação pudessem dispor de outra alternativa. Sugeriram também que houvesse mais espaços de escuta, de valorização e de proximidade dos profissionais que trabalham nas instituições com os usuários.

Outro aspecto destacado pelos entrevistados é a falta de preparo de alguns funcionários que estão à frente dos serviços:

O que falta? Em que está o despreparo? Qualidade nos serviços, e mais diretamente no profissional que atende essa população, do perfil do atendente [...] Que não é qualquer pessoa, não é um trabalho, não é um emprego qualquer como seria um caixa de banco, contabilidade de escritório [...] Está lidando com gente, com vidas, é preciso uma formação, um perfil e gostar do trabalho que faz! E nesse ponto, os serviços pecam! Técnicos, pessoas competentes, mas 
competentes enquanto profissionais, não competentes enquanto área de assistência [...] Isso dificulta muito o trabalho [...] (BRASIL, 2008a).

A capacitação para a escuta, para a formação de vínculo, para o acolhimento, implícita na fala do entrevistado quando refere "[...] não é um emprego qualquer [...] está lidando com gente”, foi também identificada como uma das demandas de moradores de rua albergados pelo estudo realizado por Bulla, Mendes e Prates (2004), que sugerem que os abrigos e albergues disponham de mais espaços de escuta e maior proximidade dos profissionais que ali trabaIham com os usuários.

Visando fazer frente a esse processo de fragmentação, a recente política nacional para inclusão social de pessoas em situação de rua tem como eixos a articulação entre os níveis de governo federal, estadual e municipal, além da interdisciplinaridade e intersetorialidade que caracterizam a integralidade no atendimento.

\section{A POLÍTICA NACIONAL PARA INCLUSÃO SOCIAL DA POPULAÇÃO EM SITUAÇÃO DE RUA}

A Política Nacional para Inclusão Social da População em situação de Rua (BRASIL, 2008) destaca como princípios: a dignidade da pessoa humana, a garantia da cidadania e direitos humanos, o direito ao usufruto da cidade, a não discriminação e a supressão de qualquer ato violento ou vexatório, de estigmas e preconceitos - o que pressupõe a capacitação do conjunto de trabalhadores que atuam nas mais diversas políticas para melhor compreensão dos múltiplos fatores que são transversais aos processos de rualização.

No que concerne às diretrizes, a política prevê a estruturação de rede de proteção incluindo as políticas de saúde, assistência social, habitação, geração de renda e emprego, cultura, sistema de promoção e garantia de direitos. Com a finalidade de dar concretude às diretrizes, o Decreto 7053/2009 (BRASIL, 2009) institui a criação de grupos temáticos para discutir alternativas de inclusão integradas, bem como a realização de estudos e pesquisas, criação de programas e serviços para a obtenção de sugestões e recepção 
de denúncias sobre a violação dos direitos desse segmento populacional.

Entre as diversas ações estratégicas que estão previstas pela Política Nacional para Inclusão Social da População em situação de Rua em cada uma dessas áreas e instâncias, como se descreve nos parágrafos seguintes (BRASIL, 2008).

Na área dos direitos humanos, além da previsão de capacitação de operadores, destaca-se a criação de ouvidorias e o combate à impunidade a atos de violência direcionados a essa população.

Na área do trabalho, estão previstos o estabelecimento de parcerias para incentivar a inserção produtiva de sujeitos em situação de rua, a promoção de processos de capacitação e o incentivo a formas cooperativadas de geração de renda e inserção produtiva.

Na área da habitação, o processo deverá se materializar a partir da inserção em programas habitacionais públicos, locação social, entre outras formas de acesso à moradia, utilizando-se como alternativas a reforma de imóveis públicos para uso habitacional e a disponibilização de imóveis vazios em centros urbanos.

Na área da assistência social, ressaltam-se a estruturação da rede de acolhida, a produção de informações e indicadores acerca desse segmento populacional, sua inclusão no Cadastro Único, no Benefício de Prestação Continuada (BPC) e no Programa Bolsa Família (PBF), além da promoção de oportunidades de trabalho e acesso a capacitação profissional e educação.

Na área da educação, a política prevê a criação de grupos de trabalhos para busca de alternativas que visem ofertar educação em meio aberto, bem como a oferta de alfabetização, flexibilização do ingresso, em qualquer época do ano, incentivo à assiduidade escolar (com uniforme, material, transporte), política de inclusão digital, além da inclusão do tema rualização na rede de ensino.

Na área da segurança alimentar, a política determina o acesso ao alimento via restaurantes populares.

Na área da saúde, que - destaque-se - apresenta o maior volume 
de ações e com maior abrangência, incluindo a participação do usuário na gestão da política, estão previstos: a atenção integral à saúde dessa população a partir de cuidados interdisciplinares e multiprofissionais; a promoção à saúde, com ênfase no programa saúde da família sem domicílio; o fortalecimento da atenção em saúde mental através dos CAPs; além da capacitação de trabalhadores da saúde, em especial os do Atendimento Móvel de Urgência (Samu) e agentes comunitários. Nessa área estão também previstos a inclusão de moradores de rua e ex-moradores de rua como agentes comunitários e o incentivo à sua participação nas instâncias de controle social do SUS.

Enfim, na área da cultura e do esporte, a política prevê o acesso a meios de informação, criação e fruição cultural; o apoio ao desenvolvimento das diversas linguagens artísticas; a realização de atividades artísticas como teatro, literatura e artesanato; a promoção de debates sobre a ressignificação da rua como espaço de produção simbólica; programas de esporte e lazer no espaço da rua; o apoio a projetos culturais que tenham a rua como temática e a promoção de ocupações que articulem cultura e geração de renda.

Sem dúvida, a implementação de uma política nacional que articula ações em áreas e instâncias tão diversas e complexas é um avanço significativo, mas um desafio que pressupõe o enfrentamento de muitas resistências. Contudo, sua legitimidade - especialmente porque pautada em estudos em que sujeitos usuários, movimentos sociais e especialistas foram escutados, tanto para a construção de um diagnóstico nacional como para a proposição de estratégias - amplia suas perspectivas de sucesso. Resta acompanhar atentamente a sua materialização, que dependerá não só da vontade política de governantes, o que pressupõe o investimento efetivo de recursos públicos, humanos e financeiros, mas também do compromisso dos operadores da política na superação de muitos limites, entre os quais se destacam a desarticulação histórica entre as políticas e a posição caudatária do social em relação ao econômico. Finalmente, ressalta-se como fundamental a capacidade de controle social da sociedade para que, nos diversos níveis de governo, a política possa ser efetivamente viabilizada, conforme o planejado, e aprimorada, a partir da prática concreta. 


\section{4 À GUISA DE UMA BREVE REFLEXÃO FINAL}

Para concluir, é importante reiterar alguns aspectos já destacados em alguns estudos e pela própria política que precisam ser observados para que as ações propostas ampliem sua efetividade.

Dentre esses aspectos, ressaltam-se o necessário reconhecimento da heterogeneidade dessa população e, como consequência, a elaboração de estratégias diversas que contemplem as particularidades desses sujeitos para possibilitar a superação dos processos de rualização, evitando abordagens massificadas, a partir da criação de serviços específicos com corpo profissional diferenciado e capacitado.

Destaca-se, ainda, que a vulnerabilidade mental dessa população identificada por diversos estudos (VIEIRA et al, 1992; CATON, 1993; SLAGG; LYONS; COOK, 1994; DIXON et al., 1995; ZLOTNICK; ROBETSON, 1996; ABREU et al., 1999) exige a priorização de atendimentos nessa área destinados a essa população, especialmente no que se refere ao tratamento da dependência química e o acompanhamento em meio aberto; e que as alternativas de capacitação profissional e geração de trabalho e renda direcionadas a esse segmento populacional precisam ser induzidas para que contemplem efetivamente a inclusão dessa população e não só a sua inserção precária e provisória, o que acaba por mascarar a exclusão e reiterá-la.

Considera-se igualmente fundamental a ampliação de investimentos em processos de acolhimento que contemplem as aspirações e características dos sujeitos usuários, além da garantia de intervenção junto aos núcleos familiares e priorização para investimentos sociais em regiões que concentram pobreza, de onde procedem esses sujeitos, buscando ações que os vinculem a sua comunidade, garantindo-lhes o direito ao convívio familiar e comunitário e articulando recursos ofertados pelas redes locais.

O investimento em processos preventivos para evitar processos de rualização ou, dito de outro modo, a proteção a quem deve proteger é também um aspecto de fundamental importância a ser considerado, pois um grande contingente de famílias vulnerabilizadas reproduz o ciclo transgeracional da pobreza. Um estudo realiza- 
do com meninos e meninas em situação de rua em Porto Alegre (REIS; PRATES, 2000) mostra que 70\% relatam episódios de violência, abandono e maus tratos vivenciados desde muito cedo e $84 \%$ enfatizam a necessidade de conseguir dinheiro (trabalho, mendicância), o que reitera a necessidade de trabalhar-se no âmbito do fortalecimento da família e da prevenção, já nessa etapa, quando é mais fácil interromper processos de rualização ainda não cristalizados (PRATES, 2011).

Outra iniciativa apontada por estudos realizados com sujeitos adultos em situação de rua destaca a necessidade da oferta de repúblicas transitórias e moradias como parte da política habitacional, sem a segregação desses sujeitos (ABREU et al., 1999).

Reitera-se o que foi apontado pelos sujeitos pesquisados no estudo nacional (BRASIL, 2008a) quanto à necessidade de capacitação de trabalhadores para a oferta de serviços públicos de qualidade (estatais e da rede conveniada) e, igualmente, de interface efetiva entre as políticas públicas e delas com as demais instâncias da sociedade para a garantia de direitos.

Por fim, ressalta-se a indispensável articulação entre estado e sociedade para a superação de estigmas e preconceitos junto ao imaginário social, a partir de socialização de pesquisas, realização de debates, uso educativo da mídia e formação de multiplicadores, de modo que esses sujeitos possam ter visibilidade - mas como sujeitos de direitos. Nesse sentido, iniciativas como a inclusão do debate sobre desigualdade e rualização como temática na rede de ensino são muito bem-vindas.

\section{REFERÊNCIAS}

ABREU, P. B. et al. Condições sociais e de saúde mental de moradores de rua adultos em Porto Alegre: relatório de pesquisa. Porto Alegre: FRGS/PUCRS/HCPA/Fasc, 1999.

BORBA, M. O "louco de rua" e a seguridade social em Porto Alegre: da (in)visibilidade social à cidadania. 2005. Dissertação (Mestrado em Serviço Social) - Programa de Pós-Graduação em Serviço 
Social, Pontifícia Universidade Católica do Rio Grande do Sul, Porto Alegre, 2005.

BRASIL. Política nacional para Inclusão Social da População em situação de rua. Brasília: MDS, 2008. Disponível em: <http://www.recife.pe.gov.br/noticias/arquivos/2297.pdf>. Acesso em: 12 jan. 2011.

BRASIL. Pesquisa Nacional sobre a População em Situação de Rua. Brasília: MDS, 2008a. Disponível em: <http://www.mds.gov.br/backup/arquivos/sumario_executivo_pop_rua.pdf>. Acesso em: 12 jan. 2011.

BRASIL. Decreto 7.053, de 23 de dezembro de 2009. Institui a Política Nacional para a População em Situação de Rua e seu Comitê Intersetorial de Acompanhamento e Monitoramento, e dá outras providências. Brasília, 2009. Disponível em: <http://www.planalto. gov.br/ccivil_03/_At02007-2010/2009/Decreto/D7053.htm>. Acesso em: 12 jan. 2011.

BROWNE, A. Family violence and Homelessness: the relevance of trauma histories in the lives of homeless women. American Journal of Orthopsychiatry, v. 63, n. 3, p. 370-381, 1993.

BULLA, L.; MENDES, J.; PRATES, J. As múltiplas formas de exclusão social. Porto Alegre: EDIPUCRS, 2004.

CASTEL, R. As Armadilhas da exclusão. In: CASTEL, R.; WANDERLEY, L. E. W.; WANDERLEY, M. B. Desigualdade e a questão social. São Paulo: Educ, 2000.

CATON, C. et al. Follow-up of chronically homeless mentaly ill men. The American Journal of Psychiatry, v. 150, n. 11, p. 1639-1642, 1993.

CEZIMBRA, L. Mulheres em situação de rua. 2001. Trabalho de Conclusão de Curso (Graduação em Serviço Social) - Faculdade de Serviço Social, Pontifícia Universidade Católica do Rio Grande do Sul, Porto Alegre, 2001.

DIXON, L. B. et al. Modify the PACT Model of Survey Homeless Person with Severe Mental Ilness. Psychiatric Services, v. 46, n. 7, p. 684-688, 1995. 
FARIAS, V. C. C. de. Possibilidades de inserção/reinserção produtiva dos moradores de rua no município de Porto Alegre. 2007. Dissertação (Mestrado em Serviço Social) - Programa de Pós-Graduação em Serviço Social, Pontifícia Universidade Católica do Rio Grande do Sul, Porto Alegre, 2007.

FRANCISCO, W. de C. e. Populações em situação de rua. 2010. Disponível em: <http://www.brasilescola.com/brasil/populacao-situacao-rua.htm>. Acesso em: abr. 2011.

MARX, Karl. Manuscritos econômico-filosóficos. Lisboa, edições 70, 1993.

OURIQUES, C. Do menino ao jovem adulto de rua portador de HIV. 2005. Dissertação (Mestrado em Serviço Social) - Programa de Pós-Graduação em Serviço Social, Pontifícia Universidade Católica do Rio Grande do Sul, Porto Alegre, 2005.

PAUGAM, S. Fragilização e ruptura dos vínculos sociais: uma dimensão essencial do processo de desqualificação social. Revista Serviço Social e Sociedade, São Paulo, ano 20, n. 60, jul. 1999.

PRATES, J. C. A igualdade formal e sua aplicabilidade prática: os descaminhos da dignidade atribuída ao negro brasileiro. 2010. Tese (Doutorado em Serviço Social) - Programa de Pós-Graduação em Serviço Social, Pontifícia Universidade Católica do Rio Grande do Sul, Porto Alegre, 2010.

. Sujeitos em situação de rua: desvendando a realidade e propondo alternativas de enfrentamento. Trabalho apresentado no I Fórum Municipal de Populações em situação de rua de Bento Gonçalves. Bento Gonçalves: PMBG, 2011.

PRATES, J. C.; ABREU, P.; CEZIMBRA L. Mulheres em situação de rua. In: BULLA et al. As múltiplas formas de exclusão social. Porto Alegre: EDIPUCRS, 2004.

PRATES, J. C.; REIS, C. N.; ABREU, P. A metodologia de pesquisa para populações de rua e as alternativas de enfrentamento pelo Poder Público Municipal. Serviço Social e Sociedade, São Paulo, n. 64, 2000. 
REIS, C. N. dos; PRATES, J. C. Fragmentos de uma metrópole: meninos e meninas em situação de rua. Porto Alegre: EDIPUCRS, 2000.

REIS, C. N. dos; PRATES, J. C.; MENDES, Jussara. A realidade dos moradores de rua de Porto Alegre. Porto Alegre: PMPA/Fesc-FSS/ PUCRS, 1994.

. Sujeitos de rua: a pesquisa como instrumento de desvendamento e intervenção na realidade social. Retrato Social, Porto Alegre, n. 1, 1996.

ROSA, C. M. M. (Org.). População de Rua: Brasil e Canadá. São Paulo: Hucitec, 1995.

SCHUCH, P. et al. Pesquisa sujeitos em situação de rua. Porto Alegre: UFRGS/Fasc, 2008.

SEVERINO, A. J. Metodologia do trabalho científico. 22. ed. São Paulo: Cortez, 2002.

SLAGG, N. B.; LYONS, J. S.; COOK, J. A. A Profile of Clients Served by a Mobile Outreach Program for Homeless Mentally III Person. Hospital and Community Psychiatry, v. 45, n. 11, p. 1139-1141, 1994.

SNOW, D.; ANDERSON, L. Desafortunados: um estudo sobre o povo da rua. Rio de Janeiro: Vozes, 1998.

VIEIRA, M. A. et al. (Org.). População de rua: quem é, como vive, como é vista. São Paulo: Hucitec, 1992.

YASBEK, M. C. A Luta pela sobrevivência na cidade. Os "homeless" ou "a população de rua". In: BOGUS, L. M. M.; WANDERLEY, L. E. W. (Org.). A Luta pela Cidade em São Paulo. São Paulo: Cortez, 1992.

ZLOTNICK, C.; ROBETSON, M. J. Sources of Income Among Homeless Adults with Major Mental Disorders or Substance Use Disorders. Psychiatric Services, v. 47, n. 2, p. 147-151, 1996. 